\title{
Assessment and regulation of the urbanized territory atmospheric air condition of the Karaganda city of the Republic of Kazakhstan
}

\author{
Yelena Tseshkovskaya ${ }^{1 *}$, Elena Golubeva ${ }^{2}$, Nataliya Tsoy $^{1}$, Aigul Oralova $^{1}$, \\ Yuriy Obukhov ${ }^{1}$, and Alma Ahmetova ${ }^{1}$ \\ ${ }^{1}$ Karaganda Technical University, Karaganda, Kazakhstan \\ ${ }^{2}$ Lomonosov Moscow State University, Moscow, Russia
}

\begin{abstract}
The work is devoted to the assessment of the atmospheric air on urbanized territories of Karaganda. This work determines the content of 11 pollutants. Measurements were carried out at 14 route posts with the maximum coverage of the entire city territory in June and January in order to obtain seasonal dynamics of atmospheric air pollution. As a result of measurements in July, the maximum single-time content of carbon monoxide, phenol, formaldehyde, hydrogen sulfide, and methyl mercaptans was recorded. In January, carbon monoxide predominates in the city's air from pollutants, and increased concentrations of hydrogen sulfide are also observed in most parts of the city. Based on the results obtained, the atmospheric pollution index was calculated for 5 substances. Measurements of the pollutants were carried out at different times of the day. It was found, that contamination in almost all analyzed substances is higher in the daytime and in the evening. The main harmful impurities in the air of Karaganda are ozone, carbon monoxide, hydrogen sulfide, phenol, formaldehyde and methyl mercaptans. Ammonia was detected periodically. Based on the results the suggestions for improvement of the atmospheric air condition in the research territory were developed and adopted.
\end{abstract}

\section{Introduction}

Considering the tendency of increasing man-induced pressure due to industrial growth on the urbanized territories, the development of regional indicators of environmental components condition, which are a kind of indicators reflecting the condition, dynamics and interaction of environmental components and ecosystems in general, has become relevant. Opportunities for improving the condition of atmospheric air are developed taking into consideration the geoecological, economic, social characteristics of specific territories with increasing man-induced pressure.

\footnotetext{
*Corresponding author: elena tsesh@mail
} 
The trend of increasing air pollution and the threat of increased environmental risk is quite noticeable in the industrial regions of the Republic of Kazakhstan, in particular in the Karaganda region.

The main sources of air pollution in the city of Karaganda are large and small industrial enterprises. According to the Department of Statistics, there are 3406 stationary sources of pollutant emissions into the air in Karaganda. Organized sources are 1975 (58\%); unorganized are 1431 (42\%). From the organized sources, 296 sources (15\%) are equipped with treatment devices.

There are several coal deposits, two large coal-fired power plants, which are also located within the city. Furthermore, the infrastructure of the city is represented by two large coal-fired power plants, which are also located within the city. In addition to these factors, a significant contribution to the anthropogenic impact on environmental components is made by the growth of the transport load.

According to the observations of the RSE "Kazhydromet" in Karaganda, it is in 6th place in terms of air pollution. The territory of Karaganda was taken as the object of the research in this scientific work. The aim of this research is to assess the current condition of atmosphere air in Karaganda to develop regional targets for improving air quality, to study sustainability and the possibilities of self-healing of the environment in the city.

The objectives of this work are:

- selection of model sites on the territory of Karaganda, exposed to industrial enteprises and transport;

- analysis of the actual measurements of air quality to assess the situation of pollution;

- to develop suggestions for improving the quality of atmospheric air in Karaganda city and avoid the threat of environmental risk.

The subject of geoecological assessment of urbanized areas is devoted to a significant amount of research aimed at studying the environmental quality and minimizing environmental risks of pollution [1-8]. However, the question of determining such a threshold level of pollution at which the geosystems of urbanized territories will be able to recover and their total destruction will not occur is not sufficiently raised.

It is obvious that creation of ecosystems protection mechanisms and ecological risk reducing is complicated and long-term task. It was decided to dwell on the issue of atmospheric pollution as the basic environment component by means of which xenobiotic pollutants can spread in other ecosystems of urbanized territories. Thus, for instance, during the long period the studies of dust are conducted, on the basis of which air pollution levels have been distinguished [4], chemical fractionation has been considered $(\mathrm{Cr}, \mathrm{Cu}, \mathrm{Ba}, \mathrm{Sr}$, $\mathrm{As}, \mathrm{Pb}$ and $\mathrm{Zn}$ ). The results show that the components that make up the dust pose a risk to human health and the environment. As the source information, data on the background concentrations of the analyzed substances are used (indicators of observation posts of the hydrometeorological service RSE "Kazhydromet" for the certain period [9, 10]). Pollution reduction is usually established in stages, taking into account the environmental situation of the territory in question, changes in production, transport infrastructure and urban planning [6]. It should be noted that, to a greater extent, the available studies to assess the ecological situation of the territories are carried out on the basis of data on the soils condition and bottom sediments [11-13], whereas atmospheric air is analyzed in sufficient detail only in the system of environmental monitoring of cities.

In this scientific work, it was decided to assess the pollution of the urbanized territory by its own measurements at selected points of the city. 


\section{Materials and methods}

In order to accomplish the assigned tasks, the authors of this article have chosen areas for air sampling in places with the greatest anthropogenic impact, such as industrial areas, motorways and various parts of residential areas. For air sampling and results processing the effective methods are used $[14,15]$.

The presented algorithm contributes to the implementation of the research tasks:

- the purpose of analyzing the ecological situation and the way to achieve it. In this case assessment of air pollution, considering climatic conditions, seasonality, daily dynamics, dispersion conditions: wind direction and speed, terrain, density and number of floors of the territory's development;

- selection of appropriate indicators and methods for their determination;

- environmental quality assessment is carried out.

Each indicator is selected on the basis of the data analysis characterizing the environment quality: the most common contaminants or non-characteristic xenobiotics for the certain territory, and the most polluted for unclear reasons areas. These indicators should include all the necessary parameters of the ecological system functioning, indicate the causal relationship, be measurable and achievable and reflect the diversity of circumstances. Assessment of the atmospheric air condition in Karaganda to establish target indicators was carried out according to the monitoring data of the regional statistics office and measurements taken by the authors [12, 15-19].

In order to regulate the quality of atmospheric air state organizations do the emissions monitoring of carbon, sulfur dioxide, nitrogen, carbon, dust, etc. The main volume of emissions from stationary sources in Karaganda comes from solid particles (dust). In fact, it is information about fact and permissible concentration in the air. An analysis of the monitoring data shows that with the beginning of the heating season in the autumn period the emission of pollutants increases, which is associated not only with the production feature of the region (which includes two large power stations in addition to enterprises) and with vehicles, but also with private houses. Private houses situated in large area of Karaganda and here coal is used as fuel.

As a result, we have air pollution by suspended solids, nitrogen oxides, sulfur and carbon. Nitrogen and sulfur oxides are very actively involved in the formation of acid rain and smog, and also these substances negatively affect the human body, both on their own and in combination, causing changes in the lungs, blood vessels, respiratory tract, etc. Therefore, for the first time in this work for Karaganda, regional indicators were developed taking into account the production, climatic, economic and geoecological characteristics of the region.

According to the statistic data analysis, the largest amount of emissions comes from sources, emissions from which are not subjected to purification. The most common pollutants of the city entering the air from industrial sources are carbon monoxide, sulfur dioxide, nitrogen oxide, hydrocarbons, and dust. Analysis of data on air pollution shows that only dust and suspended substances are purified. Gas components are difficult to subject to the purification process.

To obtain seasonal dynamics of air pollution in the city, measurements of the content of pollutants were carried out in July and January. In addition to the natural climate difference of July and January, the difference of man-induced impact is added. As a rule, it is connected with the increased impact on industrial enterprises due to the heating period. The measurements were carried out at route monitoring stations, taking into account the location of the stationary posts of the Karaganda branch of the STS "Kazhydromet", so as to cover parts of the city that do not have stationary measurement, i.e. in residential neighborhoods, near school and hospital. 
The substances that are the most common pollutants in modern cities with coal-based power and the developed road network were measured. At the same time, these pollutants are dangerous in terms of risks to public health. The locations of measurements in Karaganda are presented in Fig. 1.

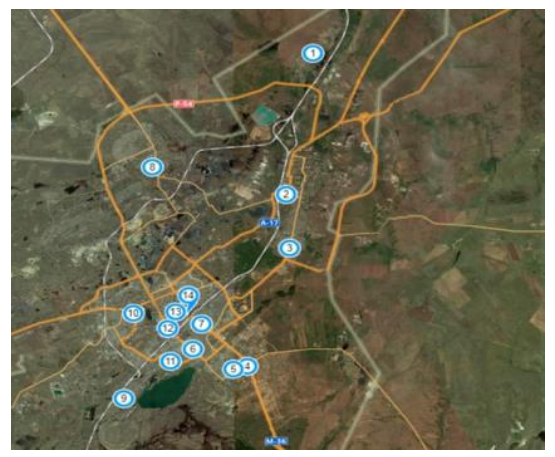

Fig. 1. Sampling sites for determining the content of the air pollutants in Karaganda (Authors' results of research)

\section{Results and discussion}

As a result of measurements, the maximum content of carbon monoxide, phenol, formaldehyde, hydrogen sulfide, methylmercaptans in the air of Karaganda in July was exceeded. (fig. 2). There is a regular fluctuation in the concentration of contaminants in the air during the day in July (fig. 3).
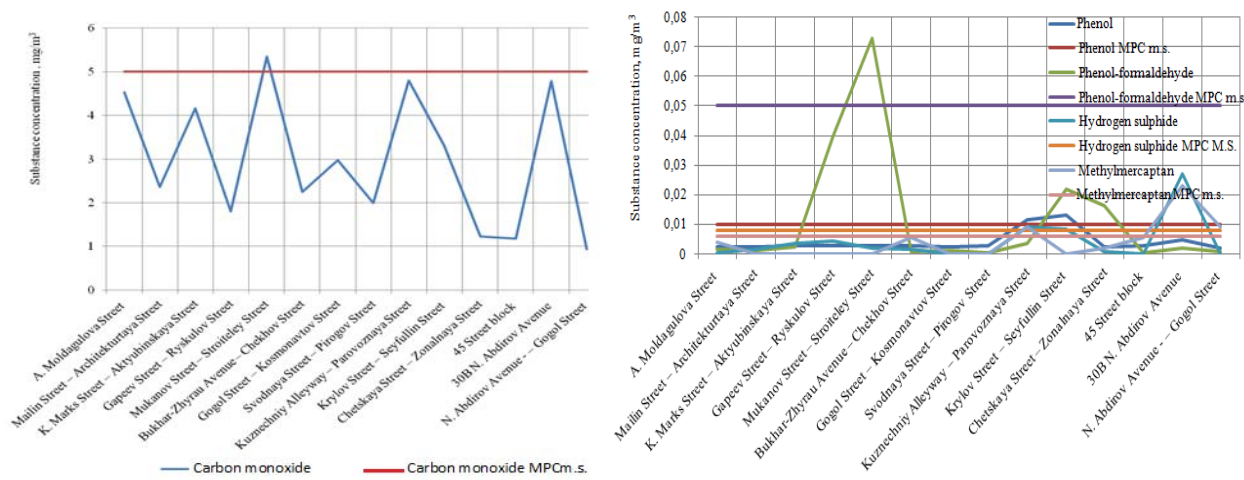

Fig. 2. Maximum one-time content of pollutants in the air in July (Authors' results of research)

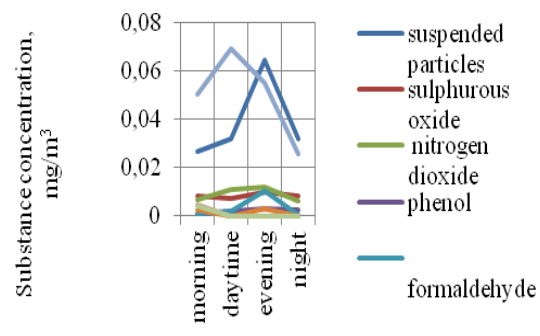

Times of Day

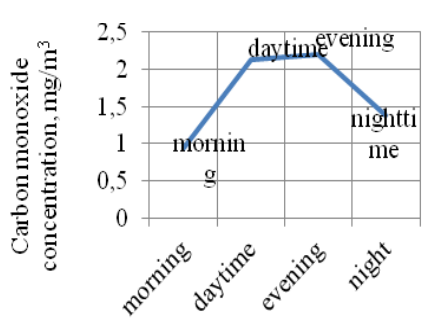

Times of Day

Fig. 3. Pollutants daily fluctuations in air (Authors' results of research) 
For most substances, the maximum concentration is reached in the evening period, accumulating during the day, when there is a gradual release of these substances from various sources, and dissipating during the night period. The peak concentration of ozone is reached in the daytime, which is associated with the formation of this substance in the atmosphere under the action of ultraviolet radiation. Atmospheric pollution index for 5 substances $\left(\mathrm{API}_{5}\right)$ for January and July is calculated with sulfur dioxide, nitrogen dioxide, carbon oxide, phenol and formaldehyde (Fig. 4).

Air quality measurements in January were made at the same points as in July (fig. 4). In January, carbon monoxide predominates in the city's air. The ozone concentration slightly decreased, at some points the daily average concentration does not reach the values of 1 TLV (threshold limitvalue). However, in most parts of the city there are elevated concentrations of hydrogen sulfide. In January, $\mathrm{C}_{12}-\mathrm{C}_{19}$ hydrocarbons and ammonia were not detected in the air.

As one can see in figure 4, the atmospheric air in Karaganda in January is more polluted than in July. The main air pollutants in January are carbon oxide, hydrogen sulfide, and ozone. Hydrogen sulfide and ozone are not included in the calculation of $\mathrm{API}_{5}$; therefore, when analyzing atmospheric pollution, they are taken into account in the standard index and in the highest frequency.

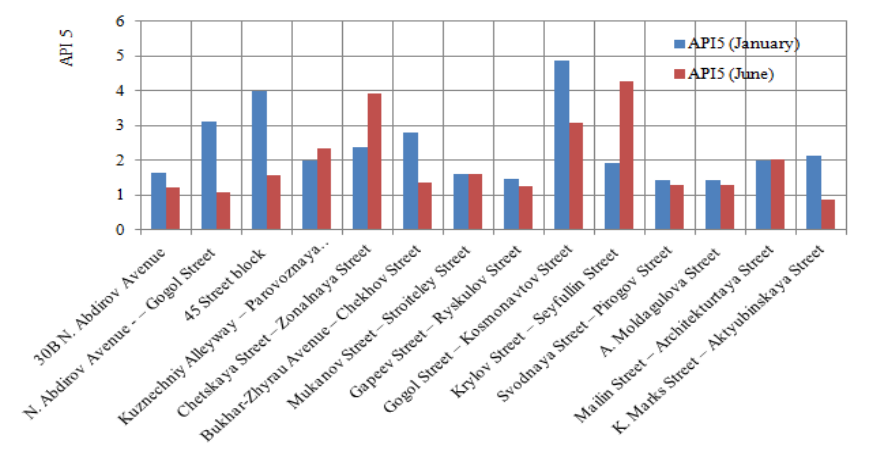

Fig. 4. Comparison of API 5 in July and January in Karaganda (Authors' results of research)

According to the data obtained, the main harmful impurities in the air of Karaganda are ozone, carbon oxide, hydrogen sulfide, phenol, formaldehyde and methylmercaptans. Oil hydrocarbons were not found in the air during measurements. Ammonia is detected periodically.

In January, when there are many small emission sources in the city (heating furnaces) that are not equipped with a sewage treatment plant, the concentration of carbon monoxide in the air significantly increases. In January, the points with the most polluted air are located at the intersection of major highways of the city in the private residential sector. To achieve the goal of this research, the ideal option is such indicators of concentrations and volumes of pollutants at which there will be no harm to public health, i.e. comply with the "safe environment" characteristic, which, as a rule, today meets to the permissible concentrations criteria.

However, the instant achievement of the permissible concentrations of pollutants is difficult in industrial areas where enterprises have been operating for more than a dozen years, in our research work has been adopted to establish improvements in indicators of pollutant concentrations in stages by periods. Leaving the situation at the current level without improvement will lead to further degradation of the environment and the deterioration of public health. In this case, it is more expedient to build on the geoecological, economic and social conditions of the territory. Such measurement as the optimization of road junctions; compliance with the mode of production in the event of 
adverse weather conditions; increasing the area occupied by greenery, with a predominance in plantings of plant species that are resistant to both local climatic conditions and to conditions of increased air pollution, designing production taking into account the relief, and wind activity of the territories for better dispersion conditions can contribute to improved ambient air quality indicators.

\section{Conclusion}

This study was intended to develop targets in the Karaganda region in order to improve the environmental situation in the region.

Analysis of statistical data showed that:

- the largest amount of emissions is from sources whose emissions are not subject to treatment;

- only dust and suspended solids are subject to cleaning (gas components are difficult to subject to the cleaning process);

- the most common pollutants of the analyzed region entering the atmospheric air from technogenic sources are: carbon monoxide, sulfur dioxide, nitric oxide, hydrocarbons, dust.

Measurements of the most common pollutants of the coal industry and the developed road network of atmospheric air were carried out in July and January. Also measurements were made in parts of the city such as residential neighborhoods, near the school and hospitals.

Measurements were carried out in the morning, afternoon and evening at the same time. Studies have shown that for most substances the maximum concentration is reached in the evening. The atmospheric pollution index for five substances $\left(\mathrm{API}_{5}\right)$ is calculated for sulfur dioxide, nitrogen dioxide, carbon oxide, phenol and formaldehyde. The atmospheric air in Karaganda in January is more polluted, than in July [20].

It was revealed that the main harmful impurities in the air of the city of Karaganda are ozone, carbon oxide, hydrogen sulfide, phenol, formaldehyde and methyl mercaptans. Oil hydrocarbons were not detected during measurements in the air. Ammonia is detected periodically. It was decided to improve the indicators for concentrations of pollutants at the MPC level in stages with a breakdown of 3 periods over 7 years to achieve MPC values.

The studies were carried out within the framework of an initiative agreement with the Administration of Karaganda (Republic of Kazakhstan). We express our gratitude to the specialists of EKOEXPERT LLP, reviewers, opponents for improving the quality of scientific work.

\section{References}

1. T.G. Goncharova, N.A. Yakovleva, Ye.S. Limeshkina, O.N. Melnik, Ye.Yu. Smirnova, V.P. Idrisova, Vestnik KazNU, Biological series, 3(49), 59-62 (2011)

2. 52.04.1.186-89. Guiding Documents, Atmospheric Pollution Control Guidelines. Moscow: Goskomgidromet USSR (1991)

3. G. Ruichao, He. Xingyuan, Environ Earth Sci, 70, 1083-1090 (2013)

4. Natural and climatic conditions. https://karaganda-region.gov.kz/rus/region_1_3, 2018.

5. Standard of the Republic of Kazakhstan 1985-2010 Protection of Nature. Atmosphere. Method for the determination of carbon black (Kazakhstan: National Standard of the Republic of Kazakhstan, Astana, 2010) 
6. X. Xuegong, X. Lifen, Y. Lei, M. Luyi, L Yaling, Environ Earth Sci, 74, 747 - 758 (2015)

7. N.A. Yakovleva, S.I. Almurzayeva, Ye.S. Limeshkina, B.Y. Ibragimova, O.A. Bogomazova, News of the Samara Scientific Center of the Russian Academy of Sciences 5(3), $644-646$ (2012)

8. Ye.A. Tseshkovskaya, E.I. Golubeva, M.K. Ibrayev, A.T. Oralova, N.K. Tsoy, M.B. Issabayeva, News of the National Academy of Sciences of the Republic of Kazakhstan. Series of geology and technology sciences, 6(438), 85-96 (2019)

9. L.K. Kazakov, Collection of articles Environmental Management: Theory, Practice, Education, 264 (Moscow, Russia, 2012)

10. L. Xiaoping, F. Linna, Environ Earth Sci, 71, 4115 - 4126 (2014)

11. Information bulletins on the state of the environment of the Republic of Kazakhstan, (, 2016, 2017, 2018).

12. Indicator tubes https://kazinmetr.kz/bd/reestr/mvi/6923/

13. Y. Jiang, H. Zhiyong, Ch. Ting, Q. Deping, Z. Xiangchen, H. Yunfeng, Environ Earth Sci, 65, 29 (2012)

14. Zh.I. Imankulov, A.A. Korchevskiy, Ye.S. Limeshkina, T.G. Goncharova, N.A. Yakovleva, S.I. PEOS, 11(97), 112 (2009)

15. Standard of the USSR 12.1.014-84. Air working area. Method for measuring concentrations of harmful substances by indicator tubes (Moscow, 2010)

16. A.B. Dale, Aquat. Sci, 67, 403 - 423 (2005)

17. Environmental monitoring bulletin. (Kazhydromet, Astana, 2018)

18. Standard of the Republic of Kazakhstan 2.297-2014. Methods for measuring mass concentration and determining the mass emission of pollutants in the exhaust gases of fuel-burning installations using various types of gas analyzers. (Astana, 2014)

19. Standard of the Republic of Kazakhstan 2.302-2014. Measurement technique, Determination of the mass concentration of harmful substances in the atmospheric air, in industrial emissions by a gas analyzer. (Astana, 2014)

20. Standard of the USSR 17.2.4.05-83. (Standard of Council for Mutual Economic Assistance 3846-82). Atmosphere. Gravimetric method for determining suspended dust particles. (Moscow, 1984) 